\title{
High thickness coating of zirconium dioxide for thermal protection of metal alloys
}

\author{
Irina Tsareva ${ }^{1, *}$, Olga Berdnik ${ }^{1}$, Maksim Maximov ${ }^{1}$, and Victor Kuzmin ${ }^{1}$ \\ ${ }^{1}$ Institute of Applied Physics of the Russian Academy of Sciences, Nizhny Novgorod, Russia
}

\begin{abstract}
A study was made of high thickness thermal barrier coating of zirconium dioxide (up to $2 \mathrm{~mm}$ ) formed by the method of high-energy plasma spraying on the intermetallic layer, and designed to protect the elements of the fuselage of aircraft.
\end{abstract}

\section{Introduction}

Thermal barrier coatings are applied to protect the fuselage's elements of aircraft from intense heat during flight in dense layers of the atmosphere, as well as from the erosion of the high-speed gas-dynamic flow of combustion products. It should provide absorption and removal from the protected surface of a significant part of the heat flux. With increasing speeds and flight times of aircraft, the operational properties of the coatings are subject to increased requirements. Today ceramics became the first class of materials competitive in comparison with metals for use at high temperatures. Entering the industry in the late $60 \mathrm{~s}$ of the XX century, it made a real revolution in materials science and in a short time became the third most widely used industrial material after metals and polymers. Currently, there is an increasing interest in plasma spray coating method, which, unlike electron beam and ionplasma methods, do not have technological limitations on the size of the processed parts.

The thermal barrier coatings studied in this work are designed for thermal protection of the fuselage elements of aircraft made of titanium and aluminum alloys. This work is devoted to the development of thermal barrier coating with an external ceramic layer, which has increased heat resistance, adhesion strength and erosion resistance.

\section{Research methodology and discussion of results}

The experiments were performed on model samples (plates $5 \mathrm{~mm}$ thick) of titanium alloy VT-20 with thermal barrier coating based on zirconium dioxide stabilized with yttrium oxide $\left(\mathrm{ZrO}_{2}+7 \% \mathrm{Y}_{2} \mathrm{O}_{3}\right)$ formed on the intermetallic sublayer of the Ni-Co-Cr-Al-Y system [1]. Coating of intermetallic and ceramic layers were carried out by the method of high-energy plasma spraying on the unit "Thermoplasma-50-1" [2]. The structure and phase composition of coating were studied by electron microscopy and X-ray diffraction analysis. The density and porosity of the coating were determined by hydrostatic weighing. Mechanical properties were investigated using the ultrasonic method of hardness measurement. The roughness of the coatings was determined from $\mathrm{R}_{\mathrm{a}}$. The adhesive 
strength of the ceramic coating was investigated using the microindentation method (on a PMT-3 microhardnesser with a load of $2 \mathrm{~N}$ ) and a scratch test.

Elements of the fuselage aircraft are made of titanium alloy VT-20, designed to manufacture parts that operate for a long time at temperatures up to $500{ }^{\circ} \mathrm{C}$. This alloy is a pseudo- $\beta$-alloy of the system "Al-Mo-V-Zr". At temperatures above $300{ }^{\circ} \mathrm{C}$, the thermophysical characteristics of the alloy vary substantially.

To ensure effective thermal protection, an attempt was made to create a thermal barrier coating designed to reduce the gradient of the temperature field. This effect is possible due to the combination of low thermal conductivity of ceramics and geometric factor (high coating thickness). But during the spraying of high thickness coatings, serious technological difficulties appeared that were linked to the concomitant heating of the titanium alloy. This in turn leads to warpage of the titanium alloy and, as a consequence, to the detachment of the coating as its thickness increases. In addition, it was necessary to create a smooth gradient of thermal expansion coefficient and hardness during the transition from the base metal material to the working outer ceramic coating layer. When parts with thermal barrier coatings operate under extreme conditions, high requirements are imposed not only on the set of operational properties, but also on its resource in connection with the possibility of premature failure of the coating. Adhesion strength of the coating is of great importance for increasing the life of the coating. To increase the coating adhesion, the following technological approaches were used:

- the surface of the titanium alloy was sand blasted with a powder of white electrocorundum with a particle size of $\sim 500 \mu \mathrm{m}$. This is done to create a surface relief in order to increase the area of contact between the substrate and the coating;

- deposition of a sublayer of the "Ni-Co-Cr-Al-Y" system with an intermetallic phase composition of $\sim 150 \mu \mathrm{m}$ in thickness;

- providing continuous heat removal from the substrate when the ceramic coating is sprayed;

- temperature control (pyrometer) during the spraying.

Powder mixture grade PNiCr20Co20Al13 (40/100) with a particle size of the main fraction $\sim 100$ microns was used for spraying of the sublayer. The elemental composition of the powder is given in Table 1, the appearance is shown in Figure 1a.

Table 1. Element composition of the powder mixture PNiCr20Co20Al13.

\begin{tabular}{|c|c|c|c|c|c|c|c|c|c|c|c|}
\hline & $\mathbf{C r}$ & $\mathbf{C o}$ & $\mathbf{A l}$ & $\mathbf{F e}$ & $\mathbf{Y}$ & $\mathbf{C a}$ & $\mathbf{N b}$ & $\mathbf{M n}$ & $\mathbf{C}$ & $\mathbf{S}$ & $\mathbf{S i}$ \\
\hline $\begin{array}{c}\text { Mass } \\
\text { fractio } \\
\text { n. \% }\end{array}$ & 18.9 & 22.4 & 14.0 & 0.15 & 0.09 & 0.06 & 0.14 & 0.01 & 0.15 & 0.01 & 0.51 \\
\hline
\end{tabular}

In high-energy plasma spraying, a sublayer with low values of total and closed porosity is formed (Table 3). The microstructure of the sublayer is a two-phase intermetallide ( $\beta$ $\left.\mathrm{NiAl}+\gamma^{\prime}-\mathrm{Ni}_{3} \mathrm{Al}\right)$. The predominance of the $\beta$-phase leads to an increase in the hightemperature stability and phase stability of the sublayer under high-temperature heating. The roughness parameter is the surface of the sublayer $\mathrm{R}_{\mathrm{a}}=7 \mu \mathrm{m}$. At higher magnification, solidified sprays of molten material during plasma spraying and individual particles of regular spherical shape (diameter $\sim 5 \mu \mathrm{m}$ ) with a dendritic microstructure inside can be seen on the surface (Fig. 2b). In the cross section, the coating has a layered microstructure (Fig. 3a). The elongated shape of the grains is linked to plasticizing the particles of the powder material, which occurs when they collide with the substrate. The boundaries of intermetallic grains are bordered by inclusions of the oxide phase. The boundaries of intermetallic grains are bordered by inclusions of the oxide phase. In the structure of the sublayer, micropores and single spherical inclusions of the drop phase $(\sim 2.5 \mu \mathrm{m}$ in size $)$ are visible. Tests of adhesion strength by the microindentation method, which is performed 
at the interface with a metal substrate, showed high bond strength. Cracking, chips and peelings were not detected (Fig. 3b).
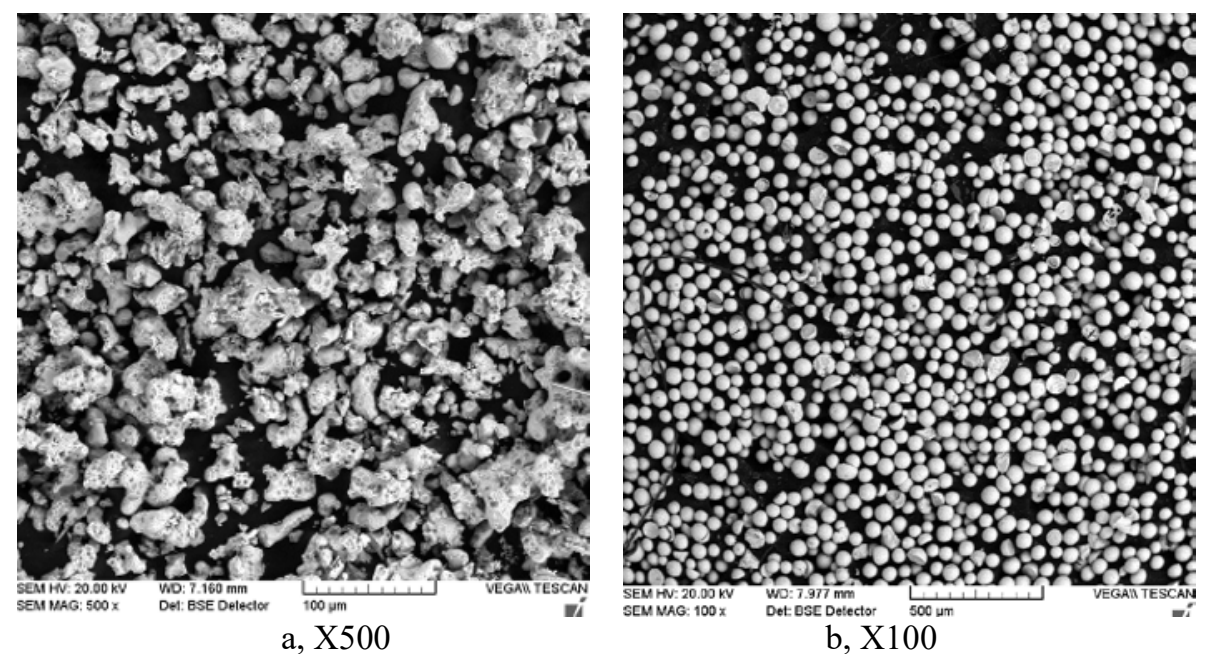

Fig. 1. Appearance of powder mixtures: a - PNiCr20Co20A113, b - Z-7Y20-80S (40/80).

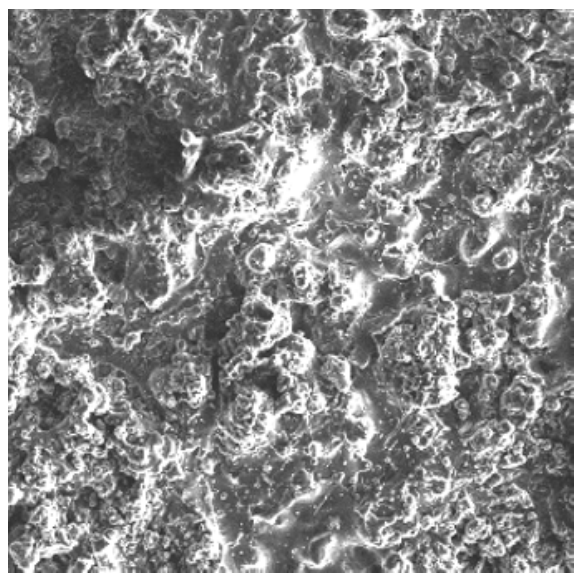

a, X500

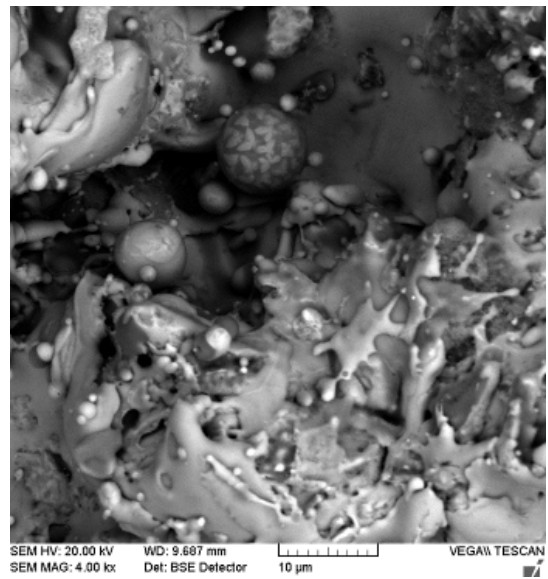

b, X4000

Fig. 2. Morphology (a), and microstructure (b) of the surface of the intermetallic sublayer

For the spraying the ceramic layer coatings was selected powder mix of the grade Z7Y20-80S (40/80) with a particle size of main fraction is $\sim 80 \mu \mathrm{m}$ [3]. The composition of the mixture is shown in table 2 , the appearance - in figure 3 a. 


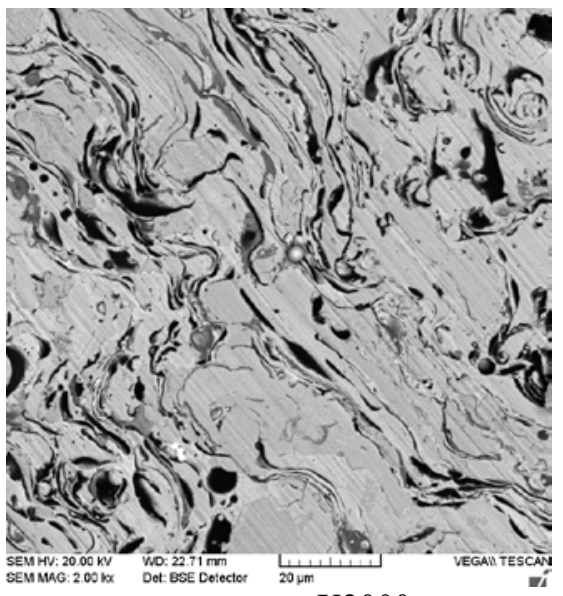

a, X2000

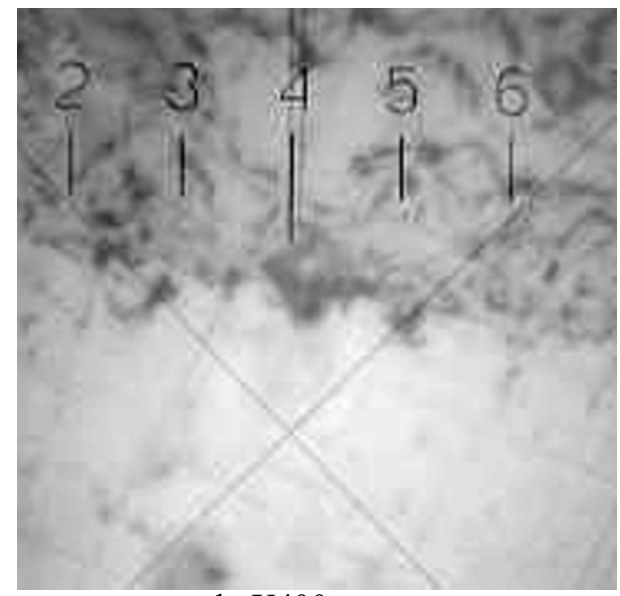

b, X400

Fig. 3. Microstructure (a) and the appearance of the structure after microindentation (b) which is performed at the interface with a metal substrate

Table 2. Composition of the powder mixture Z-7Y20-80S.

\begin{tabular}{|c|c|c|c|c|c|c|c|}
\hline & $\mathrm{ZrO}_{2}$ & $\mathbf{Y}_{2} \mathbf{O}_{3}$ & $\mathbf{S i O}_{2}$ & $\mathbf{T i O}_{2}$ & $\begin{array}{c}\mathbf{A l}_{2} \mathbf{O} \\
\mathbf{3}\end{array}$ & $\mathbf{F e O}$ & $\mathbf{C a O}$ \\
\hline $\begin{array}{c}\text { Mass. } \\
\text { fraction } \\
, \%\end{array}$ & $\approx 93.0$ & 7.0 & 0.02 & 0.02 & 0.05 & 0.05 & 0.05 \\
\hline
\end{tabular}

The phase composition of the powder is zirconium dioxide with a tetragonal type of crystal lattice $\mathrm{T}-\mathrm{ZrO}_{2}$. In the process of plasma spraying coating with a two-phase composition is formed: $\mathrm{T}-\mathrm{ZrO}_{2}+\mathrm{K}-\mathrm{ZrO}_{2}(\sim 10 \%)[4,5]$. The presence of the cubic phase improves the high-temperature stability of the coating. The phase transformation, which is linked to the thermal action of the plasma flow, for the mass fraction of yttrium oxide of $7 \%$ in accordance with [6] is realized in the temperature range from 500 to $2000{ }^{\circ} \mathrm{C}$. On the surface of the $\mathrm{ZrO}_{2}$ coating, solidified particles of the fused powder material are encountered (Fig. 4a), in the microstructure of which there are grains of spheroidal shape (Fig. 4b). The intergranular porosity in the cross-section of the coating has a predominantly disk shape (Fig. 5a). Layered microstructure (thickness $\sim 2-5 \mu \mathrm{m}$ ) is formed during the plasma treatment. Its characteristic feature is a pronounced columnar substructure with a size of $100 \mathrm{~nm}$ (Fig. 5b).

The physical and mechanical properties of the intermetallic sublayer and ceramic coating are shown in Table 3. During high-energy spraying the dense sublayer and a coating with a low total porosity of $\sim 5 \%$. It should be noted that the proportion of open porosity is small. This is an important fact, since it is open porosity that is an important factor in reducing the coating resource. Ceramic coating has a high hardness HV=9.5 GPA. The resulting complex of physical and mechanical properties is necessary in terms of ensuring such important operational characteristics of the thermal barrier coating as heat resistance, erosion resistance and thermal protection efficiency. The use of special techniques allowed spraying coating thickness of $2 \mathrm{~mm}$ on a sample thickness of $2 \mathrm{~mm}$. 


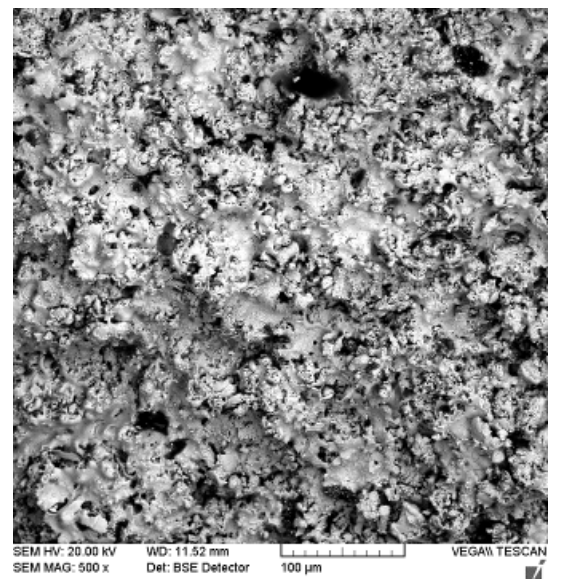

a, X500

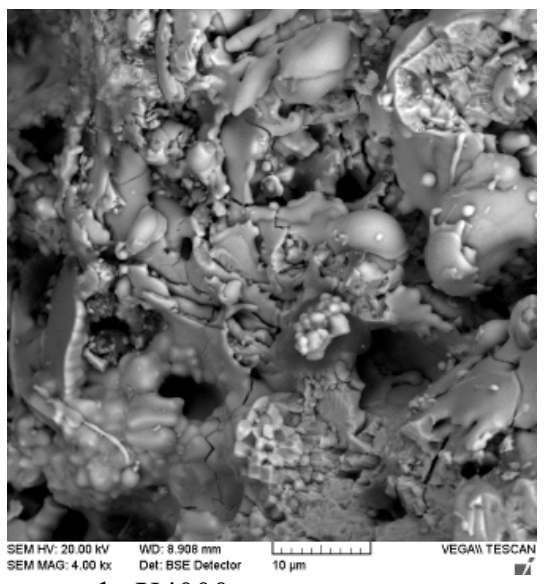

b, X4000

Fig. 4. Morphology (a) and microstructure (b) of the coating surface $\mathrm{ZrO}_{2}$

The coating was applied to prototypes with rim-forming surfaces. According to the results of bench high-temperature tests it was found that thermal barrier coating provides effective thermal protection of the surface of titanium alloy VT-20 up to the operating temperature of $\sim 1500{ }^{\circ} \mathrm{C}$. Studies conducted after the tests showed that the coating retained its integrity, phase composition and microstructure.

Work was performed within the given state task by the Institute of Applied Physics of the Russian Academy of Sciences for carrying out fundamental scientific research during 2013-2020 on a subject No. 0035-2014-0401 (No. of state registration 01201458049).

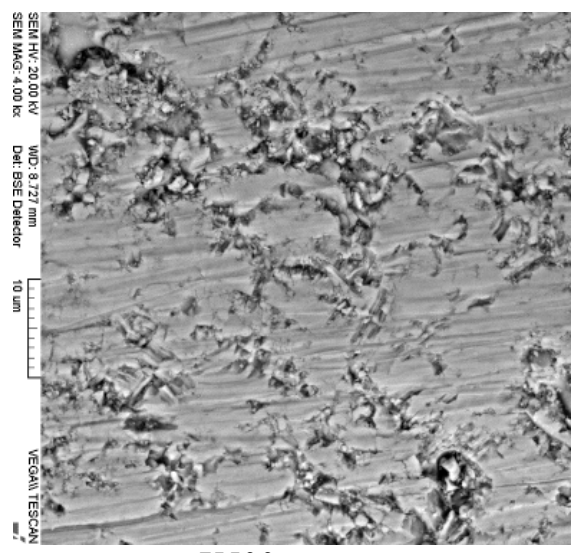

a, X500

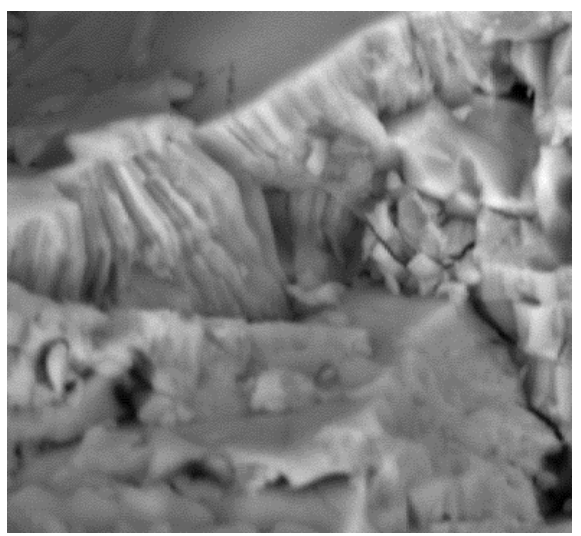

b, X4000

Fig. 5. Cross-section (a) and internal structure of $\mathrm{ZrO}_{2}$ grains (b) in $\mathrm{ZrO}_{2}$ coating layers.

\section{Conclusion}

High thickness thermal barrier coating $(2 \mathrm{~mm}$ ) based on zirconium dioxide (on the intermetallic layer) with a columnar grain structure was formed by a method of high-energy plasma spraying. This coating has a low porosity and high hardness and provides effective thermal protection of the surface of the titanium alloy VT-20 to an operating temperature of $\sim 1500{ }^{\circ} \mathrm{C}$. 


\section{References}

1. V.I. Kuzmin, E.V.Kartayev, D.V.Sergachev, E.E.Korniyenko, E.Yu. Lapushkina, Materials of the 17th Mezhd. Scientific and practical conference "Technology of hardening, drawing coverings and repair: theory and practice" (2014)

2. Yu.P.Tarasenko, I.N.Tsareva, O.B.Berdnik., Ya.A. Fel., L.A. Krivina, Vestnik of samara university. Aerospace and mechanical engineering, Samara, No. 3, pp. 85-95 (2014)

3. I.N.Tsareva, O.B.Berdnik, Yu.P.Tarasenko, Materials of reports 13 International conferences "Films and Coverings" on April 18-20, 2017, St. Petersburg, pp. 430-434 (2017)

4. M.V. Maximov, S.V. Kirikov, R.A.Vorobyov, Strengthening Technologies and Coatings (in Russian), V. 4, No. 1(157), pp. 11-16 (2018)

5. Yu.P.Tarasenko, I.N.Tsareva, O.B.Berdnik, Ya.A.Fel., V.I. Kuzmin, The Problem of mechanical engineering and reliability of cars, No. 4, pp. 89-95 (2015)

6. L.B. Getsov Materials and durability of details of gas turbines, Rybinsk, 610 p. (2010) 